recommendation. We believe the author has omitted by far the most important reason, viz., the deposit of heavy road detritus caused by the admission of storm waters, which retards the free flow of the sewage and retains a mass of decomposable matter in the sewers quite sufficient to account for the abominable effluvium emitted by the gullies and rentilators of the London system. A reason advanced for the admission of surface water into sewers given by the author, and to which much weight is attached, is the fact that it was found by the analyses of Prof. Way that the washings from the streets of London resulting from rainfall were equal in impurity to average sewage. If the surface of our streets is permitted to become so filthy that, even when diluted with rain-water, the product is only suited for adnission into the sewer, it would surely be better to turn more attention to the collection and carting away of the filth rather than to get it washed away out of sight where its presence will not be remarked until the next dry weather renders it painfully apparent. It is somewhat to be regretted that the author has not devoted a small amount of space to a subject having so important a bearing on the sanitary condition of a town and the successful operation of a system of sewerage as the scavenging of streets, especially when we consider how much improvement in this respect is needed in the metropolis. We believe that in London and other large towns, the saving in the destruction of clothing would at least pay for the proper cleansing of the streets without making any allowance for the saving of time and discomfort in locomotion.

The chapters dealing with the properties of materials and the construction of sewers, contain much useful information derived from the author's own experience and other sources, and may be consulted with much advantage by those engaged on works not only of this, but of other descriptions.

The much vexed question of sea outfalls and the influence of tidal currents on the selection of site is discussed, but it seems a pity that where ignorance and prejudice demand this mode of disposal, the author should not have laid stress upon the necessity of abstracting much of the solid matters held in suspension, thus much diminishing what is becoming an intolerable nuisance in many sea-side places. In giving so much importance to dilution with tidal water, it shotild have been borne in mind that this takes place in the direction of the breadth and depth of the volume of liquid discharged ; but in the case of the solids floating on the surface, only in the former direction, and in both cases very slowly, as may be seen by an inspection of the metropolitan outfalls. It is impossible in the space at our disposal to notice the numerous details described and illustrated ; the plates of all the more important are carefully drawn and well executed, no trouble being spared to make them thorough working drawings, while a sufficient number of woodcuts are introduced amply to illustrate the text. There are other books on this subject of a more popular nature, containing most of the information required by those who desire a general knowledge of the subject freed from too technical matters, but this is undoubtedly the best book hitherto published in this country for the student of practical sanitary science and for the engineer who requires a thorough treatment in detail of that branch of his practice.

\section{THE NAPLES ZOOLOGICAL STATION}

Mittheilungen aus der zoologischen Station zu Neapel, zugleich ein Reperatorium für Mittelmeerkunde. Erste Band, I. Heft. (Leipzig : I878.)

CINCE the foundation of the Zoological Station at Naples, nearly one hundred naturalists have worked in the laboratory connected with it, and a goodly number of papers, which have resulted from their labours, are scattered through the biological periodicals of almost all the civilised nations of Europe. Gratifying as this success must be to Dr. Dohrn, the founder of the institution, he does not show himself inclined to repose on his laurels, but aims at still further extending the scope of the station by starting two publications in connection with it. One of these, of which we have the first number before us, is publisbed in octavo size, and, as we learn from the preface, is intended for smaller papers, and general notes on the habits of animals living in the Aquarium, and other zoological topics. It will, moreover, be the medium for recording the systematic observations now being carried on by the permanent staff at the station. The second publication will be in quarto size, and will bear the title "Fauna u. Flora des Gulfes von Neapel und der angrenzenden Meeresbezirke." As its name indicates it will consist of fully illustrated monographs of the various groups of animals found in the Bay of Naples or adjoining seas. The parts may be purchased separately, or may be subscribed for by the payment of $x l$. yearly. The contents of the first part of the "Mittheilungen" promise very well. Dr. Schmidtlein, who manages the public aquarium, contributes three short papers. One of them gives an interesting account of the habits of a large number of the various animal forms living in the aquarium. A second deals with the periodic appearances of pelagic animals in the Bay of Naples during the iwo past years, and the third is a list of the breeding times of the marine forms inhabiting the Neapolitan seas. Dr. Hugo Eisig, the general manager of the station, contributes a paper of very great importance on the segmental organs of the Capitellidæ. He shows that, in some species of this group, it is normal for several segmental organs to be present in a single segment, and that the number of these organs present in a segment increases in passing from before backwards. Dr. Eisig compares the segmental organs in Annelids with the segmental tubes in Vertebrata, and points out how closely the arrangement he has found in the Capitellidæagrees with that described by Dr. Spengel in some Amphibia. There is an illustrated paper by Dr. Meyer on some points of crustacean anatomy, and two botanical papers by Drs. Falkenberg and Smitz. Dr. Dohrn himself communicates some observations on the Pycnogonidæ, in which he adduces a large amount of evidence to prove that the view as to the number of their appendages put forward by him some years ago, which was subsequently attacked by Semper, is, in all essential points, correct.

The number as a whole is very creditable to the zoological station, and we may congratulate the founder upon the continued prosperity of the institution, as evinced by its ever-increasing activity in all directions.

F. M. B. 